\title{
Unspecified Strokes: Time Trends, Determinants, and Long-Term Prognosis in the General Population
}

\author{
Alis Heshmatollah $^{\mathrm{a}, \mathrm{b}}$ Unal Mutlu ${ }^{\mathrm{a}} \quad$ L. Paloma Rojas-Saunero ${ }^{\mathrm{a}}$ \\ Marileen L.P. Portegies ${ }^{a}$ Renske G. Wieberdink ${ }^{a}$ Peter J. Koudstaal ${ }^{b}$ \\ M. Kamran Ikram ${ }^{a}$ b M. Arfan Ikram ${ }^{a}$ \\ a Department of Epidemiology, Erasmus MC University Medical Center, Rotterdam, The Netherlands; \\ ${ }^{b}$ Department of Neurology, Erasmus MC University Medical Center, Rotterdam, The Netherlands
}

\section{Keywords}

Cerebral infarction - Cerebral hemorrhage · Diagnosis .

Mortality $\cdot$ Cohort studies

\begin{abstract}
Introduction: In the absence of neuroimaging, a stroke is typically labelled as unspecified. While the majority of clinicbased stroke research focuses on hemorrhagic or ischemic stroke, in the general population, a substantial proportion of strokes remains unspecified. Objective: To investigate time trends in the occurrence and determinants of unspecified strokes and differences in patient characteristics and survival compared to ischemic or hemorrhagic stroke. Methods: We included 1,546 participants from the population-based Rotterdam Study who suffered a first-ever stroke during follow-up (1990-2016). We calculated the proportion of unspecified strokes per year and compared their characteristics between 3 time periods (1990-1999, 2000-2009, and 20102016) using a chi-square test, and furthermore investigated differences between unspecified, ischemic, and hemorrhagic stroke in patient characteristics and survival using age-
\end{abstract}

and sex-adjusted survival curves. Results: The occurrence of unspecified stroke among all strokes decreased from $75 \%$ in 1990 to $16 \%$ in 2016 . Compared to the first time period (1991-1999), diagnosis of unspecified strokes was more often done by nursing home physicians ( 13 vs. $40 \%$ ) and unspecified stroke patients had more often dementia (30 vs. $43 \%$ ) in the last time period (2010-2016). Compared to patients with ischemic or hemorrhagic stroke, patients with unspecified stroke were on average older ( 84.3 vs. 78.5 years) and had more often physical impairments and dementia. Furthermore, patients with unspecified stroke had a lower survival probability up to 10 years after stroke than those with ischemic stroke. Conclusions: The proportion of unspecified strokes decreased drastically from 75 to $16 \%$ in the last decades. Patients who do not undergo neuroimaging and therefore are classified as unspecified stroke represent an older, more frail patient group that suffers more often from multimorbidities and poor long-term prognosis than those who do undergo neuroimaging and are thus classified as ischemic or hemorrhagic stroke.

(c) 2020 The Author(s)

Published by S. Karger AG, Basel

\begin{tabular}{ll}
\hline KARGER & ( 2020 The Author(s) \\
& Published by S. Karger AG, Basel Openger \\
karger@karger.com & This article is licensed under the Creative Commons Attribution- \\
www.karger.com/ned & NonCommercial-NoDerivatives 4.0 International License (CC BY- \\
& NC-ND) (http://www.karger.com/Services/OpenAccessLicense). \\
& Usage and distribution for commercial purposes as well as any dis- \\
tribution of modified material requires written permission.
\end{tabular}

M. Arfan Ikram, MD, PhD

Department of Epidemiology

Erasmus MC University Medical Center

PO Box 2040, Rotterdam (The Netherlands)

E-Mail m.a.ikram@erasmusmc.nl 


\section{Introduction}

In patients with a clinical diagnosis of stroke, neuroimaging in an outpatient clinic or hospital is essential to distinguish between the subtypes of stroke, that is, ischemic or hemorrhagic stroke. In absence of neuroimaging, the stroke remains per definition unspecified. Reasons for the absence of neuroimaging include nonreferral by primary care physicians, death before reaching an imaging unit, or refusal of further medical care by a patient. For these reasons, the incidence of unspecified stroke is difficult to ascertain from clinic-based studies. In contrast, population-based studies that capture stroke incidence from primary and secondary care have reported that $2-52 \%$ of all strokes remain unspecified [1-9]. However, these patients are often excluded from analysis, potentially introducing selection bias since the reason that a stroke remains unspecified is most likely not at random.

In the past decades, the treatment of stroke has improved considerably with the implementation of dedicated stroke units, intravenous thrombolysis and, more recently, endovascular thrombectomy [10-12]. In addition, specialized outpatient clinics have been set up to rapidly evaluate and initiate secondary preventive treatment of patients with a mild stroke or transient ischemic attack $[13,14]$. Given abovementioned improvements in stroke care and the increased awareness of stroke symptoms among patients and physicians, it is plausible that the threshold for referral and undergoing diagnostic procedures has lowered in recent decades. This should then translate into a lower proportion of strokes remaining unspecified. Nevertheless, a certain proportion of all strokes remain unspecified, and it is unclear in what aspects these patients differ from those who undergo neuroimaging. Such insights may facilitate generalization of findings from specified stroke subtypes to the entire stroke population and may also provide leads for improved stroke management in the primary care.

Therefore, we investigated time trends in the occurrence of unspecified strokes in the past decades. We furthermore studied whether there were differences in patient characteristics and survival between patients with unspecified stroke and those with ischemic or hemorrhagic stroke.

\section{Methods}

Study Setting and Population

This study is based on the Rotterdam Study, a large prospective population-based cohort study in the Netherlands that investigates causes and consequences of chronic diseases in the general popula- tion [15]. The cohort was initiated in 1990 and was expanded in 2000 and 2006, with a total of 14,926 participants aged 45 years or older. For the current study, participants with a prior stroke at study entry $(n=459)$ and participants who did not give permission to review their medical records for incident stroke $(n=295)$ were excluded. The remaining 14,172 participants were followed up until January 2016 for the occurrence of stroke.

\section{Assessment of Stroke}

Stroke was defined according to the World Health Organization criteria as a syndrome of rapidly developing clinical signs of focal or global disturbance of cerebral function, with symptoms lasting $24 \mathrm{~h}$ or longer or leading to death, with no apparent cause other than of vascular origin [16]. History of stroke was assessed during baseline interview and verified by reviewing medical records obtained from general practitioners. After enrollment, participants were continuously monitored for incident stroke through automated linkage of the study database with files from general practitioners and nursing home physicians. Files from nursing home physicians and from general practitioners of participants who moved out of the district were also checked on a regular basis. Additional information was obtained from hospital records. The information collected on potential strokes was reviewed and structured by research physicians and verified by experienced stroke neurologists in a consensus panel. Strokes were further classified as ischemic or hemorrhagic based on neuroimaging reports. If neuroimaging was lacking, a stroke was classified as unspecified. This classification corresponds with ICD-10 codes I61, I63, and I64. Follow-up from first stroke until death or January 2016 was virtually complete (97.4\%).

\section{Assessment of Patient Characteristics}

Participants were interviewed at home every 4 years with standardized questionnaires on health status, medication use, and medical history. They additionally visited the research center for extensive physical examination. Body mass index was calculated as weight $(\mathrm{kg})$ divided by the square of height $\left(\mathrm{m}^{2}\right)$. Blood pressure was measured at the right upper arm using a sphygmomanometer during 2 consecutive readings, and the average of the 2 readings was used for further analysis. Blood samples were drawn to assess lipid and glucose levels. Diabetes mellitus type 2 was defined as a fasting glucose of $\geq 7.0 \mathrm{mmol} / \mathrm{L}$, a nonfasting or postload serum glucose of $\geq 11.1 \mathrm{mmol} / \mathrm{L}$, or use of blood glucose-lowering medication. Smoking behavior was classified as current, former, or never. Education was divided into primary; lower/intermediate education; intermediate vocational or higher general education; and higher vocational education or university. The assessment of dementia is extensively described elsewhere [17]. We used data on the patients' characteristics of the most recent center visit prior to the incident stroke.

\section{Statistical Analysis}

First, we calculated the proportion of ischemic, hemorrhagic, and unspecified stroke for every year of follow-up between 1990 and 2016. We then divided the years of follow-up into 3 time periods (1990-1999, 2000-2009, and 2010-2016) and assessed the proportion of stroke subtypes in these periods stratified by 5 -year age categories. Furthermore, we compared characteristics of participants with unspecified stroke across these 3 time periods using contingency tables and a chi-square test and stratified by sex. To compare
Time Trends, Determinants, and

Long-Term Prognosis in General Population
Neuroepidemiology 2020;54:334-342 DOI: $10.1159 / 000506130$ 
Fig. 1. Time trends of the proportion of stroke subtypes over calendar years. We calculated the proportion of ischemic (blue), hemorrhagic (red) and unspecified (green) stroke for every year of follow-up between 1990 and 2016. Over time, the proportion of unspecified stroke is decreasing over time, whereas the proportion of ischemic stroke is increasing and the proportion of hemorrhagic stroke remains stable.

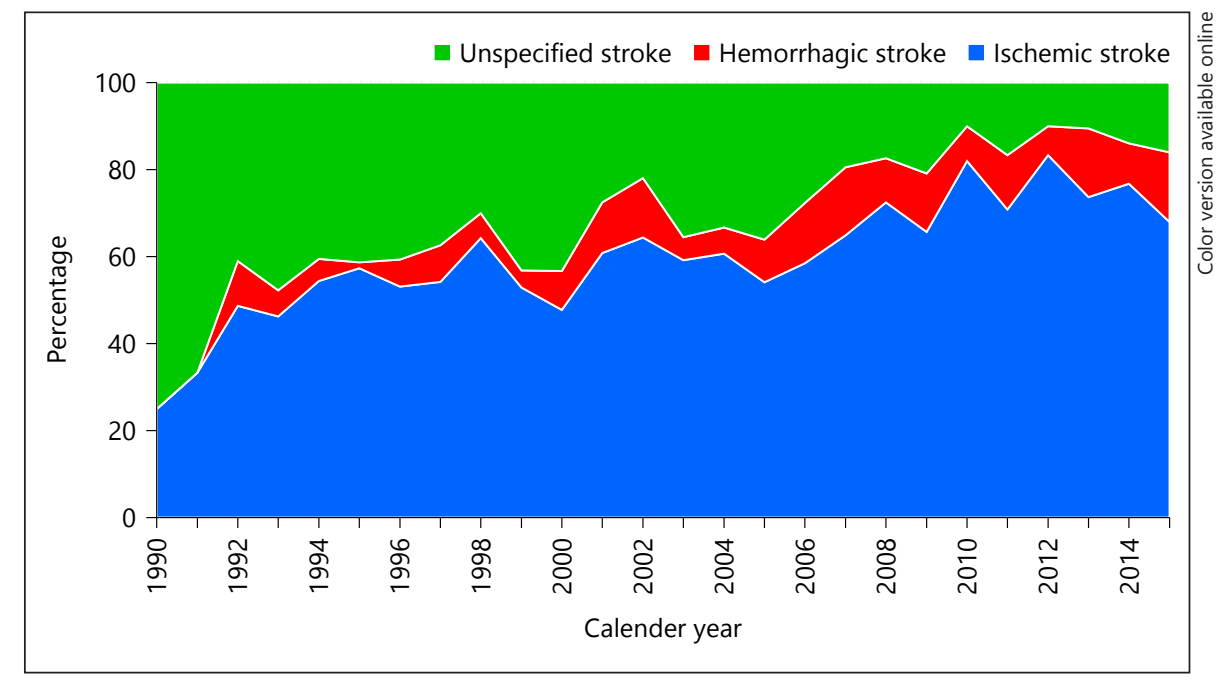

stroke subtypes, we calculated the frequencies and averages of different patient characteristics for ischemic, hemorrhagic, and unspecified stroke. Finally, we estimated survival after first stroke and the risk difference between stroke subtypes using age- and sex-adjusted survival curves. This method uses standardization to represent the survival if everyone had suffered an unspecified stroke compared to if everyone had suffered an ischemic or hemorrhagic stroke [18]. We assumed that follow-up until death was complete and used bootstrapping with 1,000 runs to construct CIs. For comparison, we added the Kaplan-Meier estimator. All analyses were performed using IBM SPSS version 24.0 and R 3.6.1 software.

\section{Results}

During a mean (SD) follow-up of 11.8 years (9.8) between 1990 and 2016, 1,546 participants suffered a stroke. Overall, 944 (61\%) were classified as ischemic, 137 (9\%) as hemorrhagic, and 465 (30\%) as unspecified stroke.

\section{Time Trends of Unspecified Stroke}

Between 1990 and 2016, the proportion of unspecified strokes decreased steadily from $75 \%$ in 1990 to $28 \%$ in 2000 and $16 \%$ in 2016 (Fig. 1). In contrast, the proportion of ischemic strokes increased from $25 \%$ in 1990 to $68 \%$ in 2016, and the percentage of hemorrhagic strokes fluctuated between 1 and $16 \%$.

Stratification per 5-year age category shows that the proportion of unspecified strokes was higher in the elderly throughout all time periods (Fig. 2). However, also within the elderly, we observed a proportional decrease of unspecified strokes over time. In the most recent time period, patients whose stroke remained unspecified were significantly more often diagnosed by nursing home physicians or the general practitioner and less often by a neu- rologist compared to earlier time periods (Table 1). Similarly, we found that fewer patients with unspecified stroke were hospitalized between 2000 and 2016 compared to the previous time periods. Furthermore, patients with unspecified stroke were more often diagnosed with dementia prior to the event.

\section{Differences between Stroke Subtypes}

Patients with an unspecified stroke were on average older, were more often women, and suffered more frequently from multimorbidity such as dementia, diabetes mellitus type 2, and prior transient neurological attacks at the time of stroke than those with either ischemic or hemorrhagic stroke (Table 2). The diagnosis in patients with unspecified stroke was primarily made by the general practitioner (52\%) or nursing home physician (24\%), whereas in patients with ischemic or hemorrhagic stroke this was mainly the neurologist (85 and $91 \%$, respectively). Stratification by sex showed that women with unspecified stroke were older, were more often diagnosed by a nursing home physician, and suffered more often from dementia than men with unspecified stroke (online suppl. Table S1, see www.karger.com/doi/10.1159/000506130).

With regard to survival, the age- and sex-adjusted survival curves show that patients with an unspecified stroke had a lower probability of survival than those with ischemic stroke. One year after the stroke, patients with unspecified stroke had an 18\% (95\% CI 13-23\%) lower probability of survival than those with ischemic stroke (Fig. 3a). This poor prognosis in patients with unspecified stroke compared to those with ischemic stroke extended to up to 10 years after stroke. However, comparing the survival to patients with hemorrhagic stroke, those with unspecified 


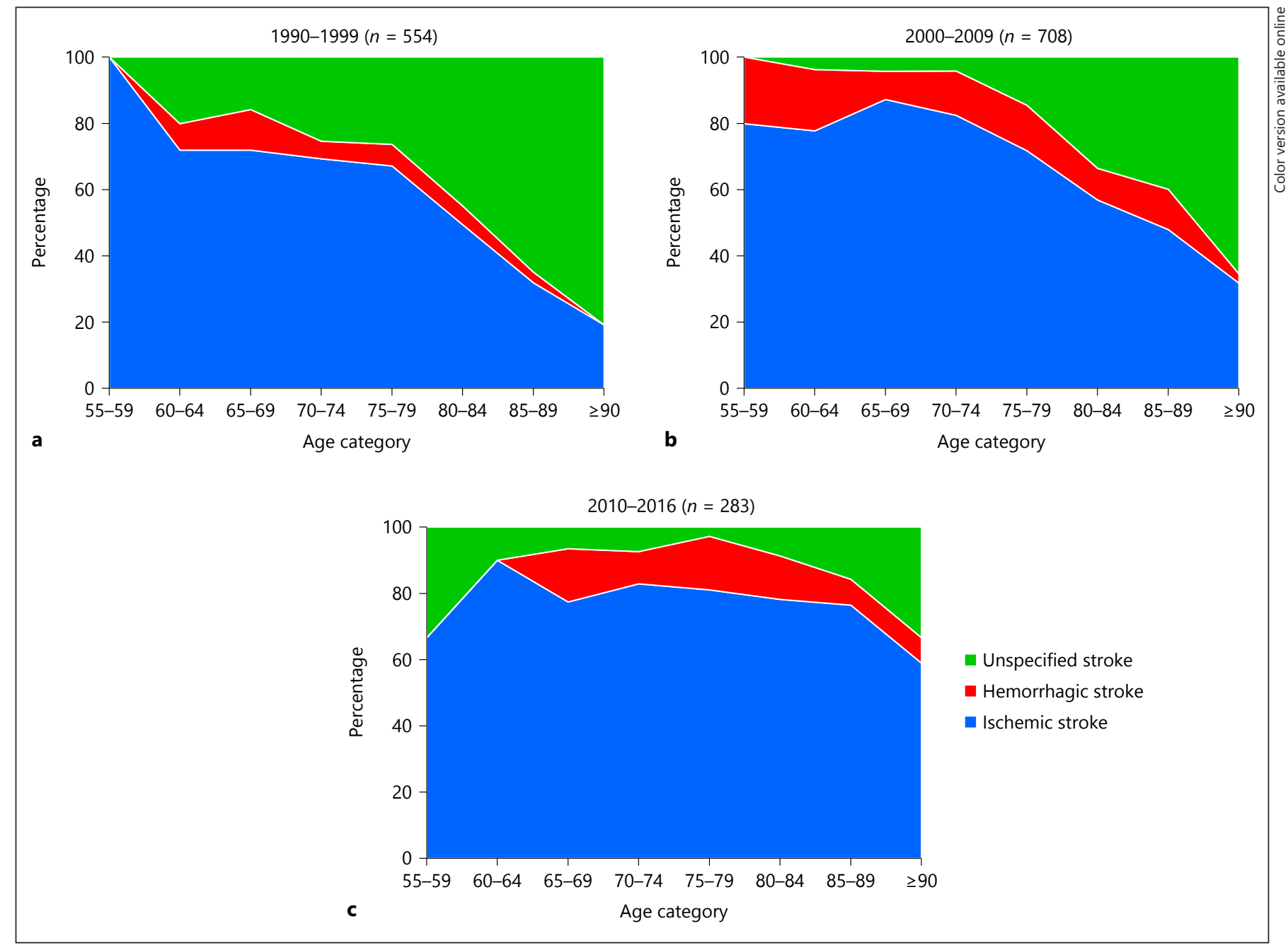

Fig. 2. Proportion of stroke subtypes over time and age categories. We divided the years of follow-up into 3 time periods and assessed the proportion of stroke subtypes in these periods stratified by 5 -year age categories. Each panel represents a different time period: 1990-1999 (a), 2000-2009 (b), and 2010-2016 (c). The pro-

stroke had a 30\% (95\% CI 19-38\%) higher survival probability after 1 year (Fig. 3b). The Kaplan-Meier estimator likewise found a lower survival probability for both unspecified and hemorrhagic stroke compared to ischemic stroke, but no substantial differences between unspecified and hemorrhagic stroke were found (Fig. 3c).

\section{Discussion}

In this prospective population-based study, we found that the occurrence of unspecified strokes decreased from $75 \%$ in 1990 to a mere $16 \%$ in 2016 . This decline was seen

Time Trends, Determinants, and

Long-Term Prognosis in General Population portion of unspecified strokes is higher in the elderly throughout all time periods. However, we observe a proportional decrease of unspecified strokes over time in all age categories including the elderly.

throughout all ages including the very elderly. Over time, the diagnosis of unspecified stroke was relatively more often made by nursing home physicians, and patients had more frequently dementia at stroke diagnosis. When comparing stroke subtypes, patients with an unspecified stroke were older, more often women and suffered more frequently from multimorbidity at stroke diagnosis than those with ischemic or hemorrhagic stroke. Also, patients with unspecified stroke had a higher probability of death immediately and up to 10 years after the event than those with ischemic stroke.

Other population-based studies have reported a proportion of unspecified strokes between 2 and 52\% [1-9] 
Table 1. Characteristics of patients with unspecified stroke by different time periods

\begin{tabular}{lccc}
\hline & $1990-1999(n=229)$ & $2000-2009(n=200)$ & $2010-2016(n=35)$ \\
\hline Age, years, mean (SD) & $84.3(8.2)$ & $86.7(6.6)$ & $85.2(10.4)$ \\
Gender, women, $n$ (\%) & $159(69.4)$ & $142(71.0)$ & $24(68.6)$ \\
Diagnosing physician, $n(\%)^{*}$ & & & \\
General practitioner & $128(55.9)$ & $90(45.0)$ & $15(42.9)$ \\
Nursing home physician & $29(12.7)$ & $58(29.0)$ & $14(40.0)$ \\
Neurologist & $39(17.0)$ & $36(18.0)$ & $2(5.7)$ \\
Other physician & $14(6.1)$ & $11(5.5)$ & $3(8.6)$ \\
Missing & $19(8.3)$ & $5(2.5)$ & $1(2.9)$ \\
Hospitalization after stroke, $n(\%)$ & & & $3(8.6)$ \\
Yes & $48(21.0)$ & $40(20.0)$ & $29(82.9)$ \\
No & $166(72.5)$ & $145(72.5)$ & $3(8.6)$ \\
Missing or unknown & $15(6.6)$ & $15(7.5)$ & $15(42.9)$ \\
Demented at stroke diagnosis, $n(\%)$ & $69(30.1)$ & $69(34.5)$ & $18(51.4)$ \\
Yes & $147(64.2)$ & $121(60.5)$ & $2(5.7)$ \\
No & $13(5.7)$ & $10(5.0)$ & \\
Missing & & & \\
\hline
\end{tabular}

* Significant difference between periods.

and show that patients under 65 years were rarely diagnosed with an unspecified stroke $[1,2,6,7,19,20]$. These are lower proportions than in our study. One of the main reasons is that the majority of these studies did not examine nursing home records but ascertained cases from hospital records, death certificates and, less often, general practitioners or family physicians in the area $[1,4,5,7-9]$. Our study shows that most patients of whom the stroke remained unspecified lived in nursing homes. Furthermore, in the nineties when imaging was not readily available, it was accepted clinical practice to subtype stroke purely based on clinical symptomatology [21, 22]. After the turn of the millennium, with scanners becoming less expensive and more accessible to routine practice, the current consensus emerged that a stroke without imaging remains per definition unspecified irrespective of symptomatology. This evolving practice likely explains why in the early years of follow-up in our study, the proportion of unspecified stroke defined according to current guidelines is relatively high, that is, $75 \%$ in 1990 . Yet, it is noteworthy that already in those early years the proportion of unspecified stroke started decreasing, that is, in 1991 to $67 \%$ and in 1992 to $41 \%$.

Studies that examined time trends showed a similar decrease over time in proportion of unspecified stroke, for example, from 52 to $9 \%[9,19]$. Several reasons could underlie this decrease in occurrence. First, it indicates that more patients with a clinical diagnosis of stroke are referred to a hospital. Current standard treatment for ischemic stroke, intravenous and endovascular, requires immediate referral and further stroke subtype specification by CT or MRI-scan. Age is also becoming less of a barrier for referral as thrombolytic and endovascular treatments do not have an upper age limit. Likewise, elderly patients benefit from being hospitalized to a stroke unit [23] and, despite the higher complication rate compared to younger patients, have a better prognosis than elderly patients without treatment $[10,24]$. Patients, who are still not referred, seem to represent a group of more frail patients declining further medical care or having several multimorbidities such as dementia and physical disabilities. In this patient group, advance directives are increasingly implemented and play an important role to ensure that the provided care and treatment are consistent with patients' wishes [25]. Our study confirms that patients with unspecified stroke were often diagnosed by a nursing home physician and had more often dementia. Second, neuroimaging is routinely performed nowadays in hospitals and therefore less strokes remain unspecified [26]. Third, due to increased awareness of stroke symptoms due to public campaigns, stroke symptoms are earlier recognized and thus less patients die before reaching an imaging unit $[7,27]$.

When comparing stroke subtypes, we found that patients with an unspecified stroke were older, more often women and displayed more multimorbidity than those with ischemic or hemorrhagic stroke. Within population-based studies, limited research has been done on the 
Table 2. Patient characteristics by stroke subtype

\begin{tabular}{|c|c|c|c|}
\hline Characteristic* & $\begin{array}{l}\text { Ischemic } \\
(n=944)\end{array}$ & $\begin{array}{l}\text { Hemorrhagic } \\
(n=137)\end{array}$ & $\begin{array}{l}\text { Unspecified } \\
(n=465)\end{array}$ \\
\hline Age at stroke, years, mean (SD) & $77.8(8.5)$ & $77.8(8.3)$ & $85.4(7.8)$ \\
\hline Gender, women, $n(\%)$ & $523(55.4)$ & $76(55.5)$ & $325(69.9)$ \\
\hline \multicolumn{4}{|l|}{ Highest educational level, $n(\%)$} \\
\hline Primary & $178(20.0)$ & $21(16.7)$ & $153(37.5)$ \\
\hline Lower/intermediate & $365(40.9)$ & $54(42.9)$ & $150(36.8)$ \\
\hline Intermediate vocational/higher general & $266(29.8)$ & $39(31.0)$ & $81(19.9)$ \\
\hline Higher vocational or university & $83(9.3)$ & $12(9.5)$ & $24(5.9)$ \\
\hline Systolic blood pressure, mm Hg, mean (SD) & $152(23)$ & $155(26)$ & $152(25)$ \\
\hline Diastolic blood pressure, $\mathrm{mm} \mathrm{Hg}$, mean (SD) & $78(12)$ & $81(14)$ & $76(13)$ \\
\hline Total cholesterol, $\mathrm{mmol} / \mathrm{L}$, mean (SD) & $5.9(1.2)$ & $5.8(1.2)$ & $6.1(1.2)$ \\
\hline $\mathrm{BMI}, \mathrm{kg} / \mathrm{m}^{2}$, mean $(\mathrm{SD})$ & $27.3(3.9)$ & $26.3(3.9)$ & $26.5(3.9)$ \\
\hline \multicolumn{4}{|l|}{ Smoking, $n(\%)$} \\
\hline Never & $290(32.7)$ & $37(28.7)$ & $183(44.7)$ \\
\hline Former & $372(42.0)$ & $63(48.8)$ & $159(38.9)$ \\
\hline Current & $224(25.3)$ & $29(22.5)$ & $67(16.4)$ \\
\hline \multicolumn{4}{|l|}{ Physical limitations before stroke, $n(\%)$} \\
\hline None to mild & $484(84.8)$ & $74(81.3)$ & $112(56.9)$ \\
\hline Moderate to severe & $87(15.2)$ & $17(18.7)$ & $85(43.1)$ \\
\hline Diabetes mellitus type $2, n(\%)$ & $173(27.3)$ & $26(28.0)$ & $85(38.1)$ \\
\hline Prior transient neurological attack, $n(\%)$ & $181(20.0)$ & $17(13.1)$ & $99(23.2)$ \\
\hline Prevalent dementia, $n(\%)$ & $67(7.3)$ & $15(11.1)$ & $153(34.8)$ \\
\hline \multicolumn{4}{|l|}{ Diagnosis made by, $n(\%)$} \\
\hline General practitioner & $15(1.6)$ & 0 & $233(50.1)$ \\
\hline Nursing home physician & $5(0.5)$ & 0 & $101(21.7)$ \\
\hline Neurologist & $888(94.1)$ & $125(91.2)$ & $78(16.8)$ \\
\hline Other physician & $27(2.9)$ & $9(6.6)$ & $28(6.0)$ \\
\hline Missing & $9(0.9)$ & $3(2.2)$ & $25(5.4)$ \\
\hline \multicolumn{4}{|l|}{ Hospitalized after stroke, $n(\%)$} \\
\hline Yes & $681(72.1)$ & $132(96.4)$ & $91(19.6)$ \\
\hline No & $243(25.7)$ & $5(3.6)$ & $341(73.3)$ \\
\hline Unknown or missing & $20(2.1)$ & 0 & $33(7.1)$ \\
\hline
\end{tabular}

* Data on blood pressure, smoking, BMI, cholesterol, HDL was missing in patients that did not visit the research center or had a stroke before their first visit (hemorrhagic $n=7$, ischemic $n=40$, unspecified $n=38$ ). Other missing data varied between 0 and 13\%, except for diabetes mellitus type 2 (36\% missing). BMI, body mass index.

difference in patient characteristics or prognosis between unspecified stroke and ischemic or hemorrhagic stroke. One study found that patients with unspecified strokes are older than those with other stroke subtypes [2], and none found sex differences that could not be explained by age $[4,5]$. Our study also suggests that women were more often diagnosed with unspecified stroke than men, probably due to a higher age and dementia at stroke diagnosis. We did not find differences in hospitalization between men and women. Previous research has also not found any racial differences between stroke subtypes [8]. Research within hospital- and registry-based studies should be interpreted with caution as they represent only a sub- group of patients with unspecified stroke that were referred to a hospital. Also, register-based studies represent a heterogeneous group of patients due to possible errors in the registration of stroke subtypes and performed examinations such as neuroimaging [28-30]. This becomes evident as these studies show a very low (1-6\%) [31-37] or very high proportion $(26-53 \%)[28,29,38-40]$ of unspecified stroke. Within these studies, patients with unspecified stroke were older [32,33] and had more disability before stroke than those with ischemic or hemorrhagic stroke [32]. Patients with unspecified stroke did not have more vascular risk factors except for a higher prevalence of diabetes mellitus and heart failure [33, 40]. Fi- 


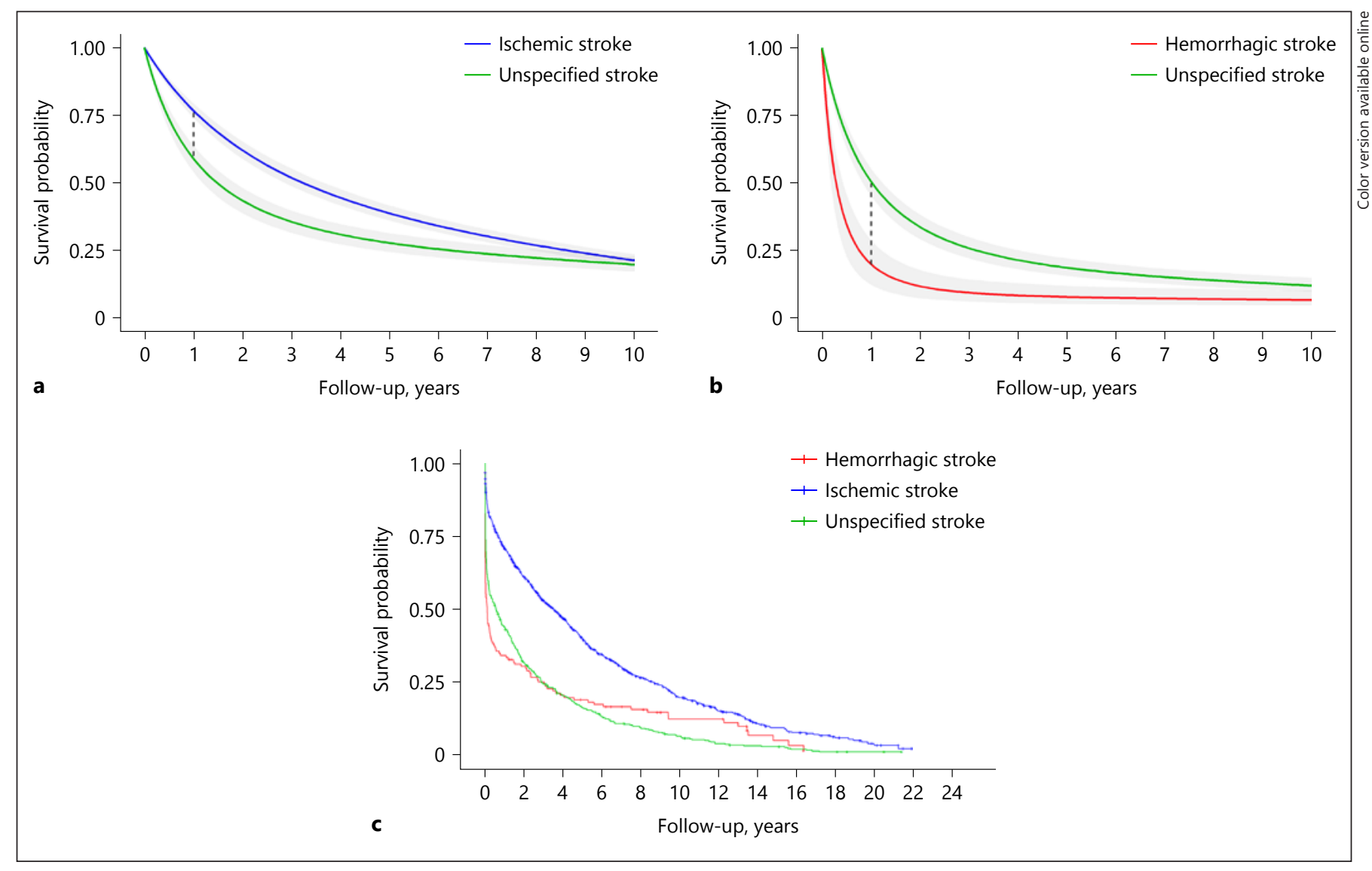

Fig. 3. Survival curves stratified by stroke subtype. Age- and sexadjusted survival curves (a, b) and Kaplan-Meier curve (c) showing the survival probability after first stroke, stratified by stroke subtype. a, b The shaded areas represent 95\% CIs and show that unspecified stroke patients have a higher probability of death than those with ischemic stroke up to 10 years after the event but a lower probability of death compared to those with hemorrhagic stroke. The Kaplan-Meier curve shows a higher probability of death in patients with unspecified stroke compared to ischemic stroke but not compared to hemorrhagic stroke. nally, hospitalized patients with unspecified stroke were less likely to receive secondary preventive medication [32] and were more likely to die if they were admitted to units other than a stroke unit compared to those with other stroke subtypes [36].

Most population-based studies showed the highest case fatality in patients with unspecified stroke ranging from 33 to $69 \%[1,2,6,20]$. Studies with a longer followup found that nearly all patients $(88-93 \%)$ with unspecified stroke died within 6-12 months $[2,5,6]$. Hospitalbased studies showed a similar in-hospital mortality of unspecified stroke, ranging from 43 to $65 \%$, and those who survived were seldom ADL independent $[9,32,33$, 37]. One study reported a lower mortality of $19 \%$, though the authors did not provide a definition of unspecified stroke [39]. None of the abovementioned studies, however, corrected for age and sex. The Kaplan-Meier estima- tor, for example, is unadjusted for covariates and therefore can be confounded. By using adjusted survival curves, we estimated that patients with unspecified stroke had a higher probability of death than those with ischemic stroke but had a better outcome than those with hemorrhagic stroke. However, an important note is that we had no information on withdrawal of care and its impact on survival in these patients. It is conceivable that patients with unspecified stroke, being older and having more comorbidities, withdrew more often from care thus resulting in poor survival after the stroke event. Hence, it is not known what the survival difference between stroke subtypes would have been had all patients received full care.

Limitations of this study need to be addressed. We did not systematically assess the severity of strokes and therefore could not determine whether patients with an unspecified stroke had a more severe stroke and therefore 
had a worse outcome. Furthermore, we were not able to differentiate between patients who were diagnosed with an unspecified stroke due to non-referral, death before reaching an imaging unit or decline of further medical care. The strengths of this study are its population-based setting which provides insight on all patients with clinical stroke symptoms who were seen by a physician, including those who were not referred. Furthermore, the age- and sex-adjusted survival curves, combined with the long follow-up, provided accurate estimates of the outcome of different stroke subtypes.

\section{Conclusion}

In conclusion, the occurrence of unspecified strokes has decreased drastically over the past 3 decades, indicating that more patients with clinical symptoms of stroke are referred to a hospital. Nevertheless, the patients who remain with an unspecified stroke represent a frail patient group who are older, more often suffer from dementia and multimorbidities, and are usually not hospitalized. Patients with unspecified stroke also have a higher probability of death than those with ischemic stroke up to 10 years after the stroke. In population-based studies, these patients should not be excluded as it introduces selection bias.

\section{Acknowledgment}

None.

\section{Statement of Ethics}

The Rotterdam Study has been approved by the medical Ethics Committee according to the Population Study Act Rotterdam Study, executed by the Ministry of Health, Welfare, and Sports of the Netherlands. All participants provided written informed consent to participate in the study.

\section{Disclosure Statement}

The authors report no conflicts of interest to declare.

\section{Funding Sources}

The Rotterdam Study is supported by the Erasmus MC University Medical Center and Erasmus University Rotterdam; The Netherlands Organization for Scientific Research (NWO); The Netherlands Organization for Health Research and Development (ZonMw); The Research Institute for Diseases in the Elderly (RIDE); The Netherlands Genomics Initiative (NGI); the Ministry of Education, Culture and Science; The Ministry of Health, Welfare and Sports; the European Commission (DG XII); and The Municipality of Rotterdam.

\section{Author Contributions}

A.H., U.M., and M.A.I. contributed to the conception and design of the work. A.H., U.M., M.L.P.P., R.G.W., M.K.I., and P.J.K. contributed to the acquisition of the data. A.H. and L.P.R.-S. analyzed the data and A.H., L.P.R.-S., M.A.I., and M.K.I. contributed to the interpretation of the data. A.H. drafted the manuscript and all authors revised the manuscript critically for intellectual content and approved the final version.

\section{References}

1 Blomstrand A, Blomstrand C, Ariai N, Bengtsson C, Björkelund C. Stroke incidence and association with risk factors in women: a 32-year follow-up of the Prospective Population Study of Women in Gothenburg. BM) Open. 2014 Oct; 4(10):e005173.

2 Di Carlo A, Inzitari D, Galati F, Baldereschi M, Giunta V, Grillo G, et al. A prospective community-based study of stroke in Southern Italy: the Vibo Valentia incidence of stroke study (VISS). Methodology, incidence and case fatality at 28 days, 3 and 12 months. Cerebrovasc Dis. 2003;16(4):410-7.

3 Feigin VL, Lawes CM, Bennett DA, Anderson CS. Stroke epidemiology: a review of population-based studies of incidence, prevalence, and case-fatality in the late 20th century. Lancet Neurol. 2003 Jan;2(1):43-53.

4 Giroud M, Delpont B, Daubail B, Blanc C, Durier J, Giroud $M$, et al. Temporal

Time Trends, Determinants, and

Long-Term Prognosis in General Population
Trends in Sex Differences With Regard to Stroke Incidence: The Dijon Stroke Registry (1987-2012). Stroke. 2017 Apr;48(4): 846-9.

5 Janes F, Gigli GL, D'Anna L, Cancelli I, Perelli A, Canal G, et al. Stroke incidence and 30-day and six-month case fatality rates in Udine, Italy: a population-based prospective study. Int J Stroke. 2013 Oct;8 Suppl A100: 100-5.

6 Kolominsky-Rabas PL, Sarti C, Heuschmann PU, Graf C, Siemonsen S, Neundoerfer B, et al. A prospective community-based study of stroke in Germany-the Erlangen Stroke Project (ESPro): incidence and case fatality at 1, 3, and 12 months. Stroke. 1998 Dec;29(12): 2501-6.

7 Manobianca G, Zoccolella S, Petruzzellis A, Miccoli A, Logroscino G. The incidence of major stroke subtypes in southern Italy: a population-based study. Eur J Neurol. 2010 Sep;17(9):1148-55.

8 Wolfe CD, Rudd AG, Howard R, Coshall C, Stewart J, Lawrence E, et al. Incidence and case fatality rates of stroke subtypes in a multiethnic population: the South London Stroke Register. J Neurol Neurosurg Psychiatry. 2002 Feb;72(2):211-6.

9 Zhang LF, Yang J, Hong Z, Yuan GG, Zhou BF, Zhao LC, et al.; Collaborative Group of China Multicenter Study of Cardiovascular Epidemiology. Proportion of different subtypes of stroke in China. Stroke. 2003 Sep;34(9):2091-6.

10 Goyal M, Menon BK, van Zwam WH, Dippel DW, Mitchell PJ, Demchuk AM, et al.; HERMES collaborators. Endovascular thrombectomy after large-vessel ischaemic stroke: a meta-analysis of individual patient data from five randomised trials. Lancet. 2016 Apr; 387(10029):1723-31. 
11 Powers WJ, Derdeyn CP, Biller J, Coffey CS, Hoh BL, Jauch EC, et al.; American Heart Association Stroke Council. 2015 American Heart Association/American Stroke Association Focused Update of the 2013 Guidelines for the Early Management of Patients With Acute Ischemic Stroke Regarding Endovascular Treatment: A Guideline for Healthcare Professionals From the American Heart Association/American Stroke Association. Stroke. 2015 Oct;46(10):3020-35.

12 Powers WJ, Rabinstein AA, Ackerson T, Adeoye OM, Bambakidis NC, Becker K, et al.; American Heart Association Stroke Council. 2018 Guidelines for the Early Management of Patients With Acute Ischemic Stroke: A Guideline for Healthcare Professionals From the American Heart Association/American Stroke Association. Stroke. 2018 Mar;49(3): e46-110.

13 Rothwell PM, Giles MF, Chandratheva A, Marquardt L, Geraghty O, Redgrave JN, et al.; Early use of Existing Preventive Strategies for Stroke (EXPRESS) study. Effect of urgent treatment of transient ischaemic attack and minor stroke on early recurrent stroke (EXPRESS study): a prospective populationbased sequential comparison. Lancet. 2007 Oct;370(9596):1432-42.

14 Luengo-Fernandez R, Gray AM, Rothwell PM. Effect of urgent treatment for transient ischaemic attack and minor stroke on disability and hospital costs (EXPRESS study): a prospective population-based sequential comparison. Lancet Neurol. 2009 Mar;8(3):23543.

15 Ikram MA, Brusselle GG, Murad SD, van Duijn CM, Franco OH, Goedegebure A, et al. The Rotterdam Study: 2018 update on objectives, design and main results. Eur J Epidemiol. 2017 Sep;32(9):807-50.

16 Hatano S. Experience from a multicentre stroke register: a preliminary report. Bull World Health Organ. 1976;54(5):541-53.

17 de Bruijn RF, Bos MJ, Portegies ML, Hofman A, Franco OH, Koudstaal PJ, et al. The potential for prevention of dementia across two decades: the prospective, population-based Rotterdam Study. BMC Med. 2015 Jul;13(1):132.

18 Hernán MA, Robins JM. Causal Inference. Boca Raton: Chapman \& Hall/CRC; 2019. [forthcoming].

19 Béjot Y, Daubail B, Jacquin A, Durier J, Osseby GV, Rouaud O, et al. Trends in the incidence of ischaemic stroke in young adults between 1985 and 2011: the Dijon Stroke Registry. J Neurol Neurosurg Psychiatry. 2014 May;85(5):509-13.
20 Ellekjaer H, Holmen J, Indredavik B, Terent A. Epidemiology of stroke in Innherred, Norway, 1994 to 1996 . Incidence and 30-day casefatality rate. Stroke. 1997 Nov;28(11):2180-4.

21 Rosamond WD, Folsom AR, Chambless LE, Wang CH, McGovern PG, Howard G, et al. Stroke incidence and survival among middleaged adults: 9-year follow-up of the Atherosclerosis Risk in Communities (ARIC) cohort. Stroke. 1999 Apr;30(4):736-43.

22 Wolf PA, D'Agostino RB, O’Neal MA, Sytkowski P, Kase CS, Belanger AJ, et al. Secular trends in stroke incidence and mortality. The Framingham Study. Stroke. 1992 Nov;23(11): 1551-5.

23 Saposnik G, Kapral MK, Coutts SB, Fang J, Demchuk AM, Hill MD; Investigators of the Registry of the Canadian Stroke Network (RCSN) for the Stroke Outcome Research Canada (SORCan) Working Group. Do all age groups benefit from organized inpatient stroke care? Stroke. 2009 Oct;40(10):3321-7.

24 Mishra NK, Ahmed N, Andersen G, Egido JA, Lindsberg PJ, Ringleb PA, et al.; VISTA collaborators; SITS collaborators. Thrombolysis in very elderly people: controlled comparison of SITS International Stroke Thrombolysis Registry and Virtual International Stroke Trials Archive. BMJ. 2010 Nov;341:c6046.

25 Pérez MV, Macchi MJ, Agranatti AF. Advance directives in the context of end-of-life palliative care. Curr Opin Support Palliat Care. 2013 Dec;7(4):406-10

26 Talwalkar A, Uddin S. Trends in emergency department visits for ischemic stroke and transient ischemic attack: united States, 20012011. NCHS Data Brief. 2015 Mar;(194):1-8.

27 Wolters FJ, Paul NL, Li L, Rothwell PM; Oxford Vascular Study. Sustained impact of UK FAST-test public education on response to stroke: a population-based time-series study. Int J Stroke. 2015 Oct;10(7):1108-14.

28 Cheng TJ, Chang CY, Lin CY, Ke DS, Lu TH, Kawachi I. State differences in the reporting of 'unspecified stroke' on death certificates: implications for improvement. Stroke. 2012 Dec;43(12):3336-42.

29 Krarup LH, Boysen G, Janjua H, Prescott E, Truelsen T. Validity of stroke diagnoses in a National Register of Patients. Neuroepidemiology. 2007;28(3):150-4.

30 Truelsen T, Krarup LH, Iversen HK, Mensah GA, Feigin VL, Sposato LA, et al. Causes of Death Data in the Global Burden of Disease Estimates for Ischemic and Hemorrhagic Stroke. Neuroepidemiology. 2015;45(3):152-60.

31 Bray BD, Paley L, Hoffman A, James M, Gompertz $\mathrm{P}$, Wolfe CD, et al.; SSNAP Collabora- tion. Socioeconomic disparities in first stroke incidence, quality of care, and survival: a nationwide registry-based cohort study of 44 million adults in England. Lancet Public Health. 2018 Apr;3(4):e185-93.

32 de Carvalho JJ, Alves MB, Viana GA, Machado CB, dos Santos BF, Kanamura AH, et al. Stroke epidemiology, patterns of management, and outcomes in Fortaleza, Brazil: a hospital-based multicenter prospective study. Stroke. 2011 Dec;42(12):3341-6.

33 Henriksson KM, Farahmand B, Åsberg S, Edvardsson N, Terént A. Comparison of cardiovascular risk factors and survival in patients with ischemic or hemorrhagic stroke. Int J Stroke. 2012 Jun;7(4):276-81.

34 Koton S, Telman G, Kimiagar I, Tanne D; NASIS Investigators. Gender differences in characteristics, management and outcome at discharge and three months after stroke in a national acute stroke registry. Int J Cardiol. 2013 Oct;168(4):4081-4.

35 Tanne D, Koton S, Molshazki N, Goldbourt $\mathrm{U}$, Shohat T, Tsabari R, et al. Trends in management and outcome of hospitalized patients with acute stroke and transient ischemic attack: the National Acute Stroke Israeli (NASIS) registry. Stroke. 2012 Aug;43(8):213641.

36 Terént A, Asplund K, Farahmand B, Henriksson KM, Norrving B, Stegmayr B, et al.; RiksStroke Collaboration. Stroke unit care revisited: who benefits the most? A cohort study of 105,043 patients in Riks-Stroke, the Swedish Stroke Register. J Neurol Neurosurg Psychiatry. 2009 Aug;80(8):881-7.

37 Ullberg T, Zia E, Petersson J, Norrving B. Changes in functional outcome over the first year after stroke: an observational study from the Swedish stroke register. Stroke. $2015 \mathrm{Feb}$; 46(2):389-94.

38 Demant $\mathrm{MN}$, Andersson $\mathrm{C}$, Ahlehoff $\mathrm{O}$ Charlot M, Olesen JB, Gjesing A, et al. Temporal trends in stroke admissions in Denmark 1997-2009. BMC Neurol. 2013 Oct; 13(1):156.

39 Lund Håheim L, Holme I, Hjermann I, Tonstad S. Risk-factor profile for the incidence of subarachnoid and intracerebral haemorrhage, cerebral infarction, and unspecified stroke during 21 years' follow-up in men. Scand J Public Health. 2006;34(6):589-97.

40 Ryglewicz D, Milewska D, Lechowicz W, Rószkiewicz M, Czlonkowska A; Polish National Stroke Registry. Factors predicting early stroke fatality in Poland. Preliminary report of the Polish National Stroke Registry. Neurol Sci. 2003 Nov;24(4):301-4. 